\title{
CONGENITAL OBSTRUCTION OF THE FEMALE URETHRA
}

BY

\author{
OSWALD ADDISON, F.R.C.S. \\ (From the Hospital for Sick Children, Great Ormond Street, London.)
}

Congenital obstruction of the male urethra by a diaphragm, or more frequently by valves of mucous membrane in connection with the veru-montanum, has been recorded from time to time, and in recent years an increasing amount of attention has been given to this condition.

In the female any kind of congenital obstruction of the urethra appears to be extremely rare, and I have been able to find so few references to it, that the following case seems worth putting on record.

O. W., female, aged 4 years, was admitted to the Hospital for Sick Children, Great Ormond Street, under Dr. Hutchison, on Oct. 4th, 1930. She had been ill for three weeks, vomiting after every meal. She had never been strong, having been undeveloped since birth. 'Always troubled with her water, never seemed to make water like anyone else, only in dribbles. She always used to strain; nearly always a motion as well.' She had suffered from prolapse of the bowel at 3 years from straining.

On admission she appeared a thin, poorly developed child, yellow, lethargic and looking very ill. The bladder was very hard and prominent above the pubes. The child was unable to empty the bladder and had to be catheterized daily, purulent urine being drawn off. The urine showed a thick deposit of pus and gave a profuse growth of streptococci. After being emptied by catheter, the bladder could still be felt as a hard supra-pubic mass. Blood urea $394 \mathrm{mgrm}$. per $100 \mathrm{c.cm}$.

The child's condition did not improve, she became more drowsy, and vomited frequently. A cystogram (sodium iodide, 13 per cent.) was taken on Oct. 16th, and showed a small bladder not quite filling the pelvis. The ureters were greatly enlarged and convoluted. Immediately behind the symphysis and continuous with the floor of the bladder was a cavity filled with the iodide solution. This cavity was about threequarters of an inch in diameter and showed a rounded lower border. It was considered to be the dilated proximal part of the urethra, and this was subsequently found to be the case.

A cystoscopic examination was made, but owing to the impossibility of obtaining a clear medium, it was unsatisfactory. On passing an instrument a slight resistance was felt about half an inch from the external meatus. The urethra was dilated and a catheter was tied in.

Patient gradually became more drowsy. The blood urea rose to $427 \mathrm{mgrm}$. per 100 c.cm. three days before death on October $23 \mathrm{rd}$.

Post-mortem EXamination.-The kidneys were enlarged and dripped pus on section. The pelves were thickened and dilated. The calices were dilated and a number of subcortical abscesses were present in each kidney. The capsule was thickened and very adherent; the kidney substance was pale and sclerosed. The ureters were both greatly dilated but not tortuous. The bladder was much thickened and moderately dilated.

A large probe was passed easily through the urethra from the bladder. The bladder was then carefully opened up from above downwards. In the middle of the urethra was found a tag of mucous membrane folded on itself and forming an 
oval projection about one-eighth of an inch long on the posterior wall on the left side. There were two small areas of damaged epithelium either of which might have been points of attachment for the free end of the tag.

\section{Discussion.}

I think the tag of mucous membrane was almost certainly the remains of a valve or diaphragm that was ruptured when the urethra was dilated and a catheter tied in. The stretching of the urethra and tying in a catheter also

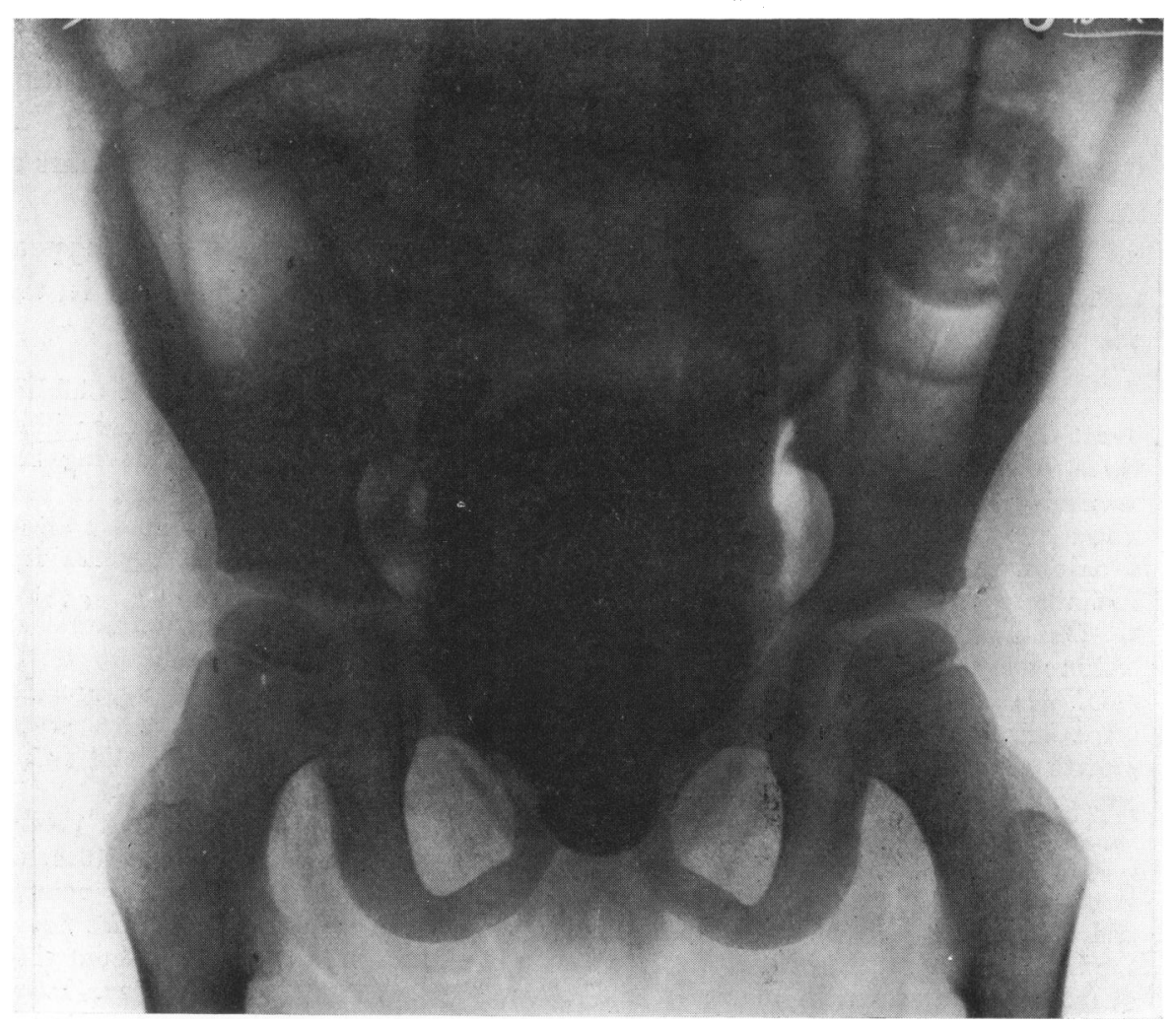

FIr. 1.-Cystogram, sodıum iodide 13 per cent. Bladder of moderate size, outline slightly irregular at sides. Behind the symphysis, continuous with the base of the bladder is a hemispherical swelling due to the dilatation of the urethra. The ureters are both greatly distended and somewhat convoluted.

probably accounted for the fact that the dilatation of the urethra proximal to the tag was not nearly so great as was expected from the cystogram.

Congenital valvular obstruction of the male urethra has been recorded many times since Langenbeck ${ }^{1}$ first published an account of the condition, but it was not recognized clinically until 1913 when Professor Young ${ }^{2}$ of Johns Hopkins Hospital published the first case diagnosed, and successfully operated upon. In 1919 with Frontz and Baldwin" he published further cases, and in 1929 with $\mathrm{McKay}^{1}$ he recorded a total of twenty-one cases with fifteen successful operations. Recently Campbell' has recorded eighteen 
more cases. In this country records of cases have been published by Poynton and Sheldon ${ }^{6}$, King and Sheldon ${ }^{7}$ and by Addison ${ }^{8}$.

Nunez" records two instances in new-born girls, where the urethra was obstructed by a diaphragm at or just within the external meatus. In one the obstruction was complete. He also reports another case, born dead, with imperforation of the anus and urethra, the latter being elongated and prolapsed for three centimetres below the pubic arch forming a transparent

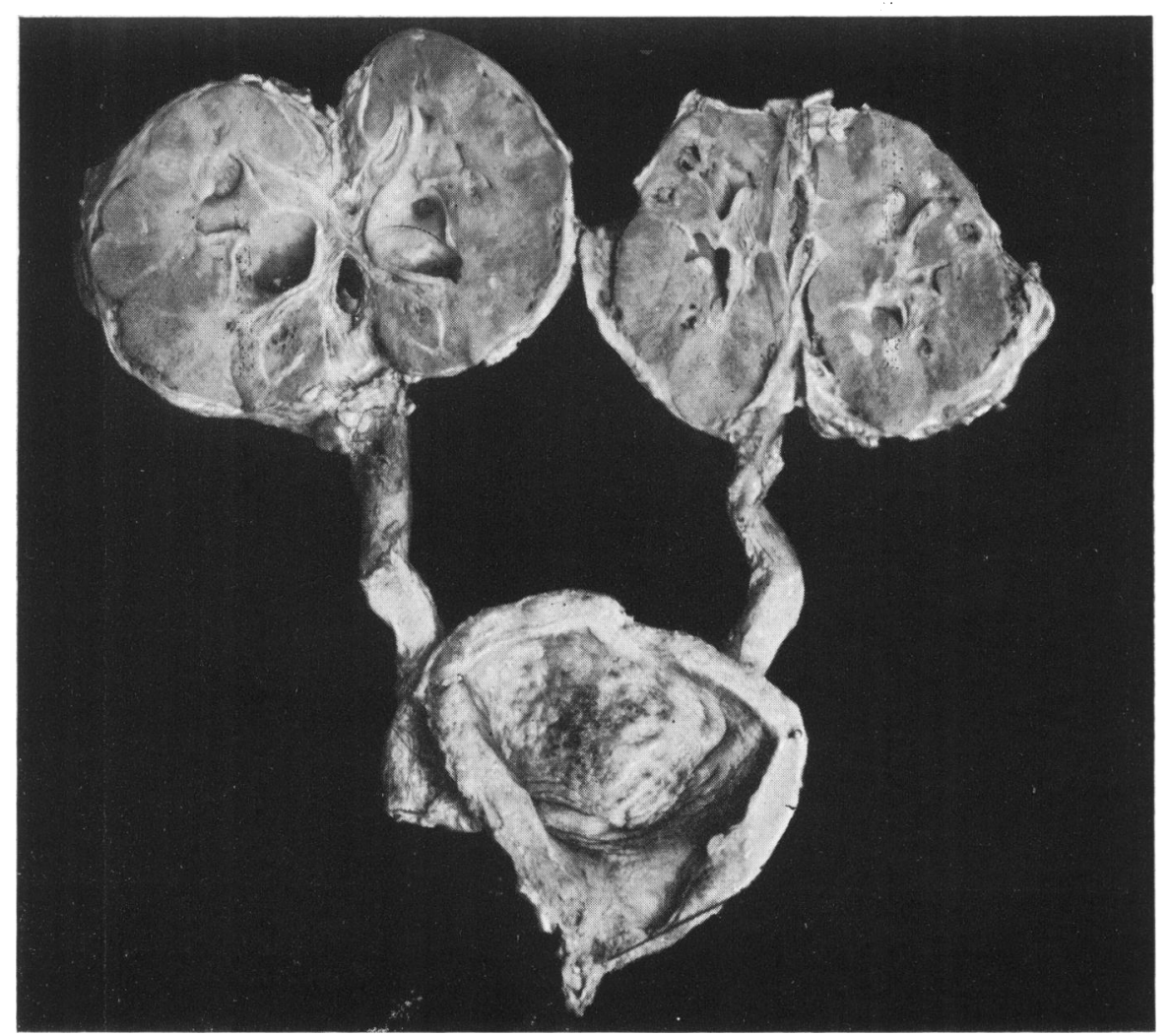

Fir: 2. Blauder and urethra opened from the front. The enlargement of the ureters and very great hypertrophy of the bladder show well, but the fold of nucous membrane in the urethra, indicated by the rod, does not stand out very clearly.

cylindrical tube. Rocher and Marc Riviere'" report a case of obstruction by diaphragm at the meatus in a new-born girl.

Nové-Josserand and Gayet" in an article on malformations of the urethra mention similar cases, including three recorded in adult life, in one of which the urethra behind the stricture was as large as a mandarin orange. They were readily cured by dilatation; no satisfactory explanation of the method of development of the malformation is given. They also quote the following:-

Enfin Barthélémy Cabrol avait déjà publié en 1552 un récit d'une delicieuse naïveté, mais d'une observation très precise, concernant une jeune fille de la ville Beaucaire. - Et trouvay son ombilic allongé de quatre doigts et semblable à la 
creste d'un coq d'Inde, et qu'elle pissait constamment par l'ombilic tout ainsi qu'elle faisait dans la ventre de sa mère, l'orifice de la vessie fermé d'une membrane épaisse d'un teston au plus, le reste bien formé, et ayant fait l'ouverture, lui mit une canule de plomb jusqu'en dedans du corps de la vessie pour tenir le conduit libre.' Symptômes et traitement, tous est déjà contenue dans cette vieille observation.

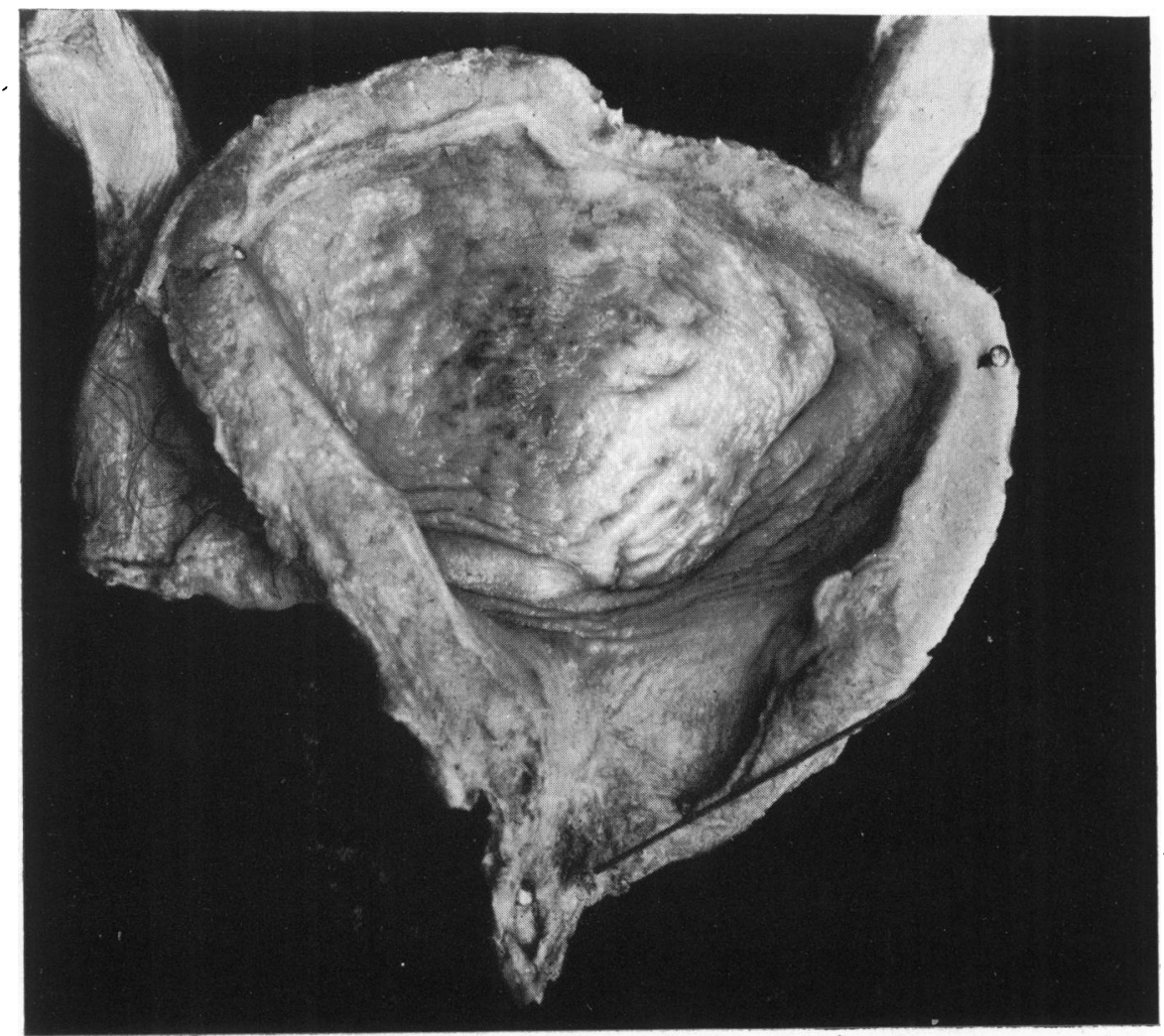

Futi. 3. Fularged view of bladder and urethra opened from the front. The rod point; to the iold of inucous me nbrane on the posterior wall of the urethra.

\section{REFERENCES.}

1. Lagenbeck, Mem. sur la lithotomie, 1802.

2. Young, H., Johns Hopkins Medical Society, 1913.

3. Young, H., Frontz, W. A., \& Baldwin, J. C., J. Urology, Balt., 1919, III, 289.

4. Young, H., \& McKay, R. W., Surg. Gynec. Obst., Chic., 1929, XLVIII, 509.

5. Campbell, E., J. Am. Med. Ass., Chicago, 1931, XCVI, 592.

6. Poynton, F. J., \& Sheldon, W., Arch. Dis. Childh., Lond., 1927, II, 252.

7. King, H. B., \& Sheldon, W., Lancet, London, 1928, ii, 1126.

8. Addison, O., Arch. Dis. Childh., Lond., 1929, IV, 255.

9. Nunez, J. E., Thèse Paris, Paris, 1882.

10. Rocher, H. L., \& Reviere, M., Bull. Soc. Obst. et Gyn., Paris, 1927, XVI, 325.

11. Nové-Josserand, G., \& Gayet, G., Encyc. franc. d'urol., Paris, 1922, V, 852. 